\title{
Cumulative Sexual Victimization and Mental Health Outcomes Among Incarcerated Women
}

Jennifer Hartsfield

Bridgewater State University, jennifer.hartsfield@bridgew.edu

Susan F. Sharp

University of Oklahoma, ssharp@ou.edu

Sonya Conner

Worcester State University, sconner@worcester.edu

Follow this and additional works at: https://digitalcommons.uri.edu/dignity

Part of the Applied Behavior Analysis Commons, Clinical Psychology Commons, Counseling Psychology Commons, Criminology Commons, Domestic and Intimate Partner Violence Commons, Health Psychology Commons, Inequality and Stratification Commons, Multicultural Psychology Commons, Personality and Social Contexts Commons, Quantitative Psychology Commons, Social Control, Law, Crime, and Deviance Commons, Social Psychology Commons, and the Social Work Commons

\section{Recommended Citation}

Hartsfield, Jennifer; Sharp, Susan F.; and Conner, Sonya (2017) "Cumulative Sexual Victimization and Mental Health Outcomes Among Incarcerated Women," Dignity: A Journal of Analysis of Exploitation and Violence: Vol. 2: Iss. 1, Article 11. https://doi.org/10.23860/dignity.2017.02.01.11

This Research and Scholarly Article is brought to you for free and open access by DigitalCommons@URI. It has been accepted for inclusion in Dignity: A Journal of Analysis of Exploitation and Violence by an authorized editor of DigitalCommons@URI. For more information, please contact digitalcommons-group@uri.edu. 


\title{
Cumulative Sexual Victimization and Mental Health Outcomes Among Incarcerated Women
}

\author{
Abstract \\ This research explores the relationship between three different types of self-reported sexual victimization \\ and subsequent mental health problems in a sample of incarcerated women. Previous literature \\ establishes a link between victimization histories and poor mental health outcomes. This study focuses \\ on sexual victimization experienced as a child, as an adolescent and as an adult, both individually and \\ cumulatively, in relation to entering prison with a mental health diagnosis as well as reporting current \\ depressive symptoms while incarcerated. Each type of victimization is significantly related to both prior \\ mental health diagnosis and current depression in prison. Furthermore, there is an additive effect on both \\ mental health diagnosis and symptoms of depression.

\section{Keywords} \\ Cumulative sexual victimization, incarcerated women, mental health, depression, childhood sexual abuse

\section{Creative Commons License} \\ (c) (i) $\ominus$ \\ This work is licensed under a Creative Commons Attribution-Noncommercial-No Derivative Works 4.0 \\ License.

\section{Acknowledgements} \\ Dignity thanks the following reviewers for their time and expertise: Kathryn Quina, Emerita As-sociate \\ Dean and Professor (Psychology and Gender and Women's Studies), University of Rhode Island; and Mary \\ Anne Layden, Assistant Professor of Clinical Psychology; Director, Sexual Trauma and Psychopathology \\ Program, Department of Psychiatry, University of Pennsylvania, USA.
}




\section{DIGNITY}

Volume 2, Issue 1, Article 11, 2017
A JOURNAL ON

SEXUAL EXPLOITATION

AND VIOLENCE

doi:10.23860/dignity.2017.02.01.11

\title{
CUMULATIVE SEXUAL VICTIMIZATION AND MENTAL HEALTH OUTCOMES AMONG INCARCERATED WOMEN
}

\author{
Jennifer Hartsfield \\ Bridgewater State University \\ Susan F. Sharp \\ University of Oklahoma \\ Sonya Conner \\ Worcester State University
}

\begin{abstract}
This research explores the relationship between three different types of self-reported sexual victimization and subsequent mental health problems in a sample of incarcerated women. Previous literature establishes a link between victimization histories and poor mental health outcomes. This study focuses on sexual victimization experienced as a child, as an adolescent, and as an adult, both individually and cumulatively, in relation to entering prison with a mental health diagnosis as well as reporting current depressive symptoms while incarcerated. Each type of victimization is significantly related to both prior mental health diagnosis and current depression in prison. Furthermore, there is an additive effect on both mental health diagnosis and symptoms of depression.
\end{abstract}

\section{KEYWORDS}

Cumulative sexual victimization, incarcerated women, mental health, depression, childhood sexual abuse

$\mathrm{W}$

HILE THE UNITED STATES now has many female correctional facilities, women still are often treated by the system as if they are the same as men, from the design of prisons to the programs and treatments that are offered (Chesney-Lind, 2003; Chesney-Lind \& Pasko, 2004; Shelden, 2001). This is significant in light of the increased numbers of women who are being incarcerated. In 2012, there were 101,289 incarcerated women in state facilities (Carson \& Golinelli, 2013), a significant increase from the 68,468 female prisoners in 1995 (Harrison \& Beck, 2005). This increase has not been due to women becoming more criminal; it is due to policy and mandatory sentencing procedures for drug offenses that became popular in the late 1980's (ChesneyLind \& Pasko, 2004; Covington \& Bloom, 2003; Sharp, 2014; Shelden, 2001).

However, the pathways through which women become involved in the criminal justice system have been argued to be different from male crime and criminality (Belknap \& Holsinger, 2006; Chesney-Lind, 1986). One common pathway for women involves victimization, subsequent development of mental health problems and self-medication of those problems (Owen, 1998; Sharp, 2014). Indeed, the most common reason for female incarceration is drug-offending (Sharp, 2014), which is likely an outgrowth of girls and women reacting to the strains of abuse and victimization by self-medicating, leading to their arrests for 
drug offenses. Furthermore, without appropriate intervention, these women will leave prison with the same issues. Thus, how women are treated while incarcerated should ideally reflect their unique needs.

Sexual victimization is disproportionately a female problem (Catalano, Smith, Snyder \& Rand, 2009; Finkelhor \& Leatherman, 1994; Reddington \& Kreisel, 2004), with girls being the majority of childhood sexual abuse victims (Clark et al., 2012; Finkelhor \& Leatherman, 1994). The same is true for the victims of adolescent and adult sexual assault and rape (Catalano, Smith, Snyder \& Rand, 2009; Reddington \& Kreisel, 2005). More specifically, less than $10 \%$ of adult sexual assault victims are male (Clark et al., 2012).

However, women offenders continue to be treated like male offenders, thus ignoring gendered needs (Marcus-Mendoza \& Wright, 2003). The results can be devastating to women who have histories of trauma and mental illness such as depression or PTSD (Covington, 2003). Stephanie Covington and Barbara Bloom (2003) point out the need to "do no harm" (p. 10) in the criminal justice system, proposing we must be aware of the additional damage that prison can do to women with histories of victimization (Covington \& Bloom, 2003). For example, the regular operating procedures and dynamics of a prison can re-trigger PostTraumatic Stress Disorder (PTSD) in traumatized women, feeding the powerlessness that many women felt prior to incarceration (Marcus-Mendoza \& Wright, 2003; Bloom, Owen \& Covington, 2004; Covington \& Bloom, 2003; Heney \& Kristiansen, 1998). Furthermore, the power matrix of the correctional system, a mostly male-run and operated institution, can reinforce the gendered order of males dominating and victimizing females (Heney \& Kristiansen, 1998). Eventually, most women who are in prison will be released back into their communities, often with the responsibility of raising their children. Their experiences within the criminal justice system will directly impact their chances for success upon release. Therefore, clear awareness of women prisoners' trauma histories can help inform policies and programs to intervene and address their issues.

The importance of recognizing the role of trauma and victimization is very important. Traumatic childhoods have been linked to negative outcomes in adults in the medical field. In 1995, the Centers for Disease Control (CDC), in partnership with Kaiser Permanente, began conducting the Adverse Childhood Experiences (ACE) study. This study surveyed over 17,000 HMO members about a variety of health issues as well as their childhood histories of victimization and household dysfunction (Felitti et al., 1998). The research was grounded in the idea that household dysfunction and different types of abuse were interrelated and could have a long-term effect on mental and physical health (Felitti et al., 1998; Edwards et al., 2003; Dube et al., 2003). Felitti et al. (1998) found that people who experienced one adverse event in childhood had a $65 \%$ to $95 \%$ chance of experiencing two or more. Utilizing the same data, a later study found that women were more likely than men to report most types of adverse childhood experiences (such as sexual abuse and household dysfunction), with the exception of physical abuse (Dube et al,. 2003). Additionally, they found a significant relationship between the number of adverse childhood events a person experienced and current depression. Similarly, Edwards and colleagues found a significant relationship between the number of adverse childhood experiences and poor mental health in adulthood (Edwards et al., 2003). The ACE model has been applied to prisoners as well (Sharp, Peck \& Hartsfield, 2012), linking adverse childhood experiences to an increased likelihood of daily drug use before incarceration. 
It is important to note that the ACE study sampled individuals who had health insurance, which could mean better access to health care and treatment than is typical of incarcerated women. The differences are more evident when educational level is considered. The ACE study consisted of a sample where almost 40\% had graduated from college, a much higher level of education than the current study where $63 \%$ reported high school or less as the highest level of education. We use a sample of incarcerated women who most likely have had poorer access to healthcare and resources than those in the ACE study. In the current paper, focus on adverse experiences is limited to sexual victimization. Three forms of sexual victimization are analyzed both separately and cumulatively to gain information on the effect of sexual victimization on mental health outcomes in a sample of incarcerated women.

Several studies have linked early childhood sexual abuse to further incidence of sexual assault later in life. In a sample of college students, Humphrey and White (2000) found that childhood sexual abuse predicted adolescent victimization, and adolescent victimization predicted victimization as a college student. Similarly, a longitudinal study of females found that girls who experienced childhood sexual abuse were twice as likely to be sexually victimized later in life (Barnes, Noll, Putnam \& Trickett, 2009).

The three types of sexual victimization examined in our study-childhood, adolescent and adult-have each been linked to negative outcomes. Childhood sexual abuse has been linked to a variety of negative outcomes including depression and PTSD in adulthood (Dube et al., 2005; Reddington \& Kreisel, 2005). Similarly, adolescent girls who experience sexual victimization are more likely to have symptoms of PTSD, depression, and anxiety disorders than girls who have not been assaulted (Krupnick et al., 2004; Gidyz \& Koss, 1989). Adult survivors of sexual victimization suffer from a wide range of negative consequences as well, including self-blame, PTSD, depression and anxiety disorders.

This study will measure the prevalence of the three types of sexual victimization survivors in state prison facilities in a southwestern state in the United States. Then, it will explore the relationship between diagnosis with a mental health disorder before incarceration as well as current levels of reported depression and sexual victimization. We hope to further the literature on women and crime by examining three types of victimization-childhood sexual abuse, sexual assault before age 18 and rape after the age of 18-to partial out the mental health effects of each category. From these three types of sexual victimization, a scale will then be created to explore the cumulative effects of experiencing multiple types of sexual victimization on past and current mental health. Prior research indicates that sexual victimization may be linked to mental illness in female prisoners, suggesting the need for specialized treatment. This study calls attention to the specialized needs of a significant portion of incarcerated females in order to make a compelling case for different prison practices, such as changes to the prison environment that would be less traumatizing, expanded access to counseling, and therapies designed to address the trauma these women have experienced in their life (Covington, 2003).

\section{Women, Trauma and Mental Illness}

The relationship between trauma or strain and mental health is well-documented. Finkelhor and Browne (1985) give a framework of four dynamics that cause life-long trauma. These "traumagenic dynamics" are traumatic sexualization, betrayal, stigmatization, and powerlessness. The effects on the victim vary 
within the four dynamics, according to the type of trauma and the reaction to the trauma that those around the victim have. These reactions to childhood sexual abuse include the inappropriate development of sexuality, negative self-images, problems with trust, and feelings of shame or guilt. As a result of these reactions, some survivors may participate in delinquent or aggressive actions to give the illusion that they are tough and powerful. It is evident from past research with both female prisoners and the general population that chronic lifelong victimization is prevalent. Women who experience one are often victims of many types of abuse across their life span (Banyard, Williams \& Siegel, 2001; Dube et al., 2003; Felitti et al.,1998). Furthermore, women who experience multiple victimizations in childhood and adolescence suffer from a wide range of psychological difficulties that impact mental health later in life (Walsh et al., 2011). Women prisoners, in general, have higher victimization rates than women in the general population (Sharp, 2014).

Using a modified strain theory approach (Agnew, 1992; Agnew, 2005; Sharp, 2014), we argue that one common pathway for women into prison results from strain, often stemming from sexual victimization. Our theoretical approach suggests that women and girls who experience sexual victimization are at risk to begin self-medicating with illegal drugs in adolescence or adulthood if they do not have personal resources such as high self-esteem, a sense of mastery or strong social support. Because of their relative powerlessness in society, due not only to their sex but also to the impoverished backgrounds of most women prisoners, these women get trapped into a downward spiral, eventually ended up in prison (Owen, 1998; Sharp, 2014). It is noteworthy that women and girls who lack power and support are far more likely than more affluent women to translate their victimization experiences into drug use, and more likely among those who do respond with drug use to lack the power to stay out of prison. Women prisoners tend to be "multiply marginalized" (Owen, 1998), unable to obtain interventions to deal with their trauma and equally unable to fight charges they may get. Thus, they are the ones who end up in prison.

\section{Childhood Sexual Abuse}

Female prisoners have a much higher rate of childhood sexual abuse than women in the general population. Most experts agree that an accurate estimation is about 50\% (Asberg \& Renk, 2012; Gilfus, 2002; Heney \& Kristiansen 1998; Marcus-Mendoza \& Wright, 2003; McClellan, Farabee \& Crouch, 1997; Zlotnick, 1997), compared to a rate in the general population of about 30\% (Asberg \& Renk, 2012; Heney \& Kristiansen, 1998).

There is a significant difference between incarcerated women and the general population regarding abuse histories; however, this does not mean that childhood sexual abuse causes criminality. While many incarcerated females share this type of history, the majority of women who are abused as children never commit a crime (Browne \& Finkelhor, 1986; Heney \& Kristiansen, 1998). In addition, it is hard to tease out the effects of the abuse from other negative factors in the childhood environment because many of the women who were sexually abused as children also experienced environmental factors associated with a greater likelihood of committing a crime (Heney \& Kristiansen, 1998; Sharp, 2014; Sharp, Peck \& Hartsfield, 2012). Studies that use the ACE data show multiple types of abuse, as well as household dysfunction, can contribute to problems lasting well into adulthood (Dube et al., 2003; Edwards et al., 2003; Felitti et al., 1998). However, other research has reported that more than one experience of sexual victimization across the life span was associated with increased mental 
health problems; even after accounting for other lifetime trauma, those who were sexually victimized had more mental health problems (Banyard, Williams \& Siegel, 2001).

\section{Mental Illness in Incarcerated Women}

Many women prisoners have problems with depression, bipolar disorder, anxiety, and Post Traumatic Stress Disorder (PTSD), often a function of their histories of abuse and victimization (Banyard, Williams \& Siegel, 2001). Incarcerated women are more likely to be involved with mental health services before incarceration and have more psychological problems than women in the community (Asberg \& Renk, 2012; Bloom, Owen \& Covington, 2004). Nationally, about $18 \%$ of the American population suffers from a mental illness (SAMSHA, 2014). In contrast, seventy-three percent of women entering prison have a mental disorder. In addition, this is often related to past abuse and victimization. Prisoners who have a history of mental illness report past physical or sexual abuse and victimization two to three times more often than prisoners without mental illness (James \& Glaze, 2006). Furthermore, in one study of incarcerated women, 48.2\% met the criteria for PTSD, 87.1\% reported one or more past traumatic events, and 40\% reported childhood sexual abuse (Zlotnick, 1997).

Building on the Adverse Childhood Experiences study, Messina, Grella, Burdon, and Prendergast (2007) measured childhood adverse events and mental health in a sample of drug addicted male and female prisoners. They found that women were $10 \%$ more likely than men to report sexual abuse and $27 \%$ more likely to report that the sexual abuse was continual. In addition, being female was significantly related to several mental health categories (dissociation, depression, anxiety, sexual problems, and sleep disturbance). Furthermore, this study found a cumulative effect of abuse on mental health.

\section{RESEARCH QUESTIONS AND HYPOTHESES}

The purpose of the current study was to compare women prisoners who reported they had been victims of sexual victimization to those without sexual victimization histories to illustrate the special circumstances and needs of abused women within the prison system. Based on the reported relationship between sexual victimization and mental illness in prior research, we expected to find that women who reported experiencing sexual victimization have a higher rate of mental health diagnoses before imprisonment than those who did not. We anticipated that due to the traumagenic effects of any type of sexual victimization, each type of sexual victimization (childhood, adolescence, adulthood) would be significantly related to mental health problems. Furthermore, based on existing literature, we anticipated that these types of sexual victimizations may have a cumulative effect. Women who had experienced more than one type of victimization should be more likely to report prior mental health diagnoses as well as have higher levels of current depression.

H1 Women who reported that they had experienced sexual abuse as a child will be more likely to report being diagnosed with a mental disorder before incarceration than prisoners who did not report childhood sexual abuse.

H2 Women who reported being raped before the age of 18 by one or more peers will be more likely to report being diagnosed with a mental disorder before incarceration than prisoners who did not report childhood rape. 
H3 Women who reported being raped after the age of 18 will be more likely to report being diagnosed with a mental disorder before incarceration than prisoners who did not report adult rape.

H4 There is an additive effect of sexual victimization, with each addition of another type of sexual victimization being associated with a higher likelihood of being diagnosed with a mental disorder before incarceration.

H5 Women who experienced sexual abuse as children will score higher on the CESD-R, indicating higher levels of current depression, than those who did not report childhood sexual abuse.

H6 Women who experienced rape before age 18 will score higher on the CESD$\mathrm{R}$ than those who did not report rape before age 18 .

H7 Women who experienced rape as an adult will score higher on the CESD-R than those who did not report rape as an adult.

H8 There is an additive effect of sexual victimization, with each addition of another type of sexual victimization being associated with higher scores on the CESD-R.

\section{METHODS}

\section{Participants and Procedure}

The data for this IRB approved study come from 2007, 2008, and 2009 surveys of women prisoners in a southwestern state. At the researchers' request, the Department of Corrections drew random, stratified samples of women that were housed in state correctional facilities in a southwestern state that ranged in security level from community corrections to maximum security. The sample was stratified according to race, age, time in system and offense type and this was representative of the prison population. No prisoner was surveyed more than once over the three-year period. The sample consisted of 830 participants. The survey instrument was composed of sixty-four questions, including demographic questions, questions about subjects' childhoods, criminal histories, and mental health issues. The following variables were used in the current analyses.

\section{Demographics}

The demographic characteristics of the sample are displayed in Table 1 . The mean age of the sample was 36.7 ( $\mathrm{Age}$ ), with self-reported ages ranging from 18 to 69 . In regards to race, $413(49.8 \%)$ of the sample self-identified as White. One hundred and seventy-two (20.7\%) self-identified as Black, ${ }^{1}$ the largest minority category, followed by Native American ( $\mathrm{n}=171,20.6 \%)$. Hispanics and other races accounted for 64 (7.7\%). From these categories, dummy variables were created; Black (those who self-reported their race as black were coded 1, and all others were coded 0), Native American (all those who indicated Native American or Native American and white were coded 1, and all others were coded 0, and Other (any responses other than white, black or Native American were coded 1 and all else were coded 0 ). White was the omitted category in the analyses.

\footnotetext{
${ }^{1}$ While the percentage black is lower than in most studies, this state has a much smaller African American population, approximately $7 \%$ of the state's population.
} 


\section{Independent (Sexual Victimization) Variables}

Three separate measures and one cumulative measure of sexual victimization were created. Participants were asked, "When you were a child (under age 18), were you ever sexually abused by anyone that was at least five years older than you?"2 Four hundred fifty-seven (55.1\%) of the women indicated that they had been sexually abused as a child, consistent with previous research. Childhood Sexual Abuse (CSA) was coded 1 if the subject indicated childhood sexual abuse, and all others were coded 0 .

The variable Rape under Age 18 was created using the question, "Apart from other sexual experiences you had growing up, did a boy or group of boys force you or threaten you with harm in order to have sex with you?" The response choices were yes or no which were coded 1 and 0 respectively. Of the responses, $171(20.6 \%)$ of the women reported experiencing a rape by peers before the age of 18.

Table 1. Frequencies of Demographic Characteristics and Variables $(\mathrm{N}=830)$

\begin{tabular}{lcc}
\hline & $\mathrm{N}$ & Percent \\
\hline Race/Ethnicity & 413 & \\
White & 172 & 49.8 \\
Black & 171 & 20.7 \\
Native American & 64 & 20.6 \\
Other & Range & 7.7 \\
& $18-69$ & Mean \\
Age & & 36.68 \\
\hline
\end{tabular}

Rape over Age 18 was created using the question, "As an adult (over age 18), have you ever been the victim of rape or sexual abuse?" There were three answer choices, yes, in the last year, yes, more than a year ago, and no." The responses were recoded so that either affirmative response was coded 1 and no was coded 0. Of the 830 valid responses, 331 (39.9\%) indicated that they had experienced rape past the age of 18 .

To create a sexual victimization score, Cumulative Victimization, we summed Childhood Sexual Abuse, Rape under Age 18, and Rape over Age 18, resulting in scores that ranged from 0 to 3 where scores of 0 indicated no report of any of the events and 3 indicated the report of all three types of victimization. Of the 830 valid responses, 259 (31.2\%) reported no victimization, 276 (33.3\%) reported one, 202 (24.3\%) reported two, and 93 (11.2\%) reported experiencing all three types of victimization.

2 Although not included in the current study, the questionnaire did ask participants whether the abuse consisted of fondling, forcing to touch the private areas of the perpetrator and/or intercourse. However, in the current study, we do not differentiate between the types of childhood sexual abuse. 


\section{Dependent (Mental Illness) Variables}

The respondents were asked a series of questions about diagnosis of a mental illness before incarceration, one of which was, if you have ever been diagnosed, what was the diagnosis? Respondents were asked to write in their response. There were 830 valid responses, with 367 (44.2\%) reporting a Mental Health Diagnosis before incarceration. The CESD-R (Radloff, 1977; Eaton, Smith, Ybarra, \& Tien, 2004) was included in the survey as a measure of the women's Current Depression. This is a highly validated and often used measure of current depressive symptomology. Normally, scores over 21 are considered indicative of the possibility of major depression (Center for Epidemiological Studies Depression Scale, n.d.). The values in the current study ranged from 10-78.41 with a mean of $41.36(\mathrm{SD}=10.85)$. Alpha for this scale was .909 .

Table 2. Frequencies of Dependent and Predictor Variables $(\mathrm{N}=830)$

\begin{tabular}{lcc}
\hline & $\mathrm{N}$ & Percent \\
\hline $\begin{array}{l}\text { Dependent Variables } \\
\begin{array}{l}\text { Mental Health Diagnosis (prior to incar- } \\
\text { ceration) }\end{array}\end{array}$ & 367 & 44.2 \\
& Range & Mean \\
Current Depression/CESD-R (last week) & $10-78.41$ & 41.36 (SD 10.85) \\
Sexual Abuse Variables & & \\
$\quad$ Childhood Sexual Abuse & 457 & 20.6 \\
$\quad$ Rape Under Age 18 & 171 & 39.9 \\
$\quad$ Rape Over Age 18 & 331 & 31.2 \\
$\quad$ Cumulative Victimization & & 33.3 \\
No victimization & 252 & 24.3 \\
One type of victimization & 272 & 11.2 \\
Two types of victimization & 202 & \\
All three types of victimization & 93 &
\end{tabular}

Note: Two cases were coded as missing on the Rape over age 18 variable.

\section{RESULTS}

To analyze these data, eight separate models were run. The first four hypotheses share the same dependent variable: mental health diagnosis. Mental health diagnosis was a dichotomous variable, so logistic regression analysis was used in this set of analyses. The last four hypotheses have the same dependent variable: current level of depression as measured by the CESD-R scale. The CESD-R scale was an ordinal scale with a normal distribution. For the purpose of this analysis, the scale was treated as a continuous variable, making ordinary least squares regression an appropriate method for analysis. 


\section{Sexual Victimization and Mental Illness}

Table 3 shows the results of the logistic regression of Mental Health Diagnosis on each of the sexual victimization variables. The results for Hypothesis 1 are presented in Model 1. After controlling for age and race, experiencing childhood sexual abuse increased the odds of being diagnosed with a mental health disorder by $107 \%$ ( $\mathrm{p} \leq .001)$. The only control variable that was significant was Black; being black decreased the likelihood of receiving a mental health diagnosis by $47 \%(\mathrm{p} \leq .001)$.

The results for Hypothesis 2 are presented in Model 2. After controlling for age and race, the Rape under Age 18 increased the likelihood of being diagnosed with a mental illness before incarceration by $123 \%$ than for those who did not experience a rape during childhood $(\mathrm{p} \leq .001)$. The only control variable that was significant was Black. Being black decreased the odds of having a Mental Health Diagnosis by $49 \%$ ( $\mathrm{p} \leq .01)$.

The results for Hypothesis 3 are presented in Model 3. Controlling for age and race, the relationship between experiencing an adult rape and being diagnosed with a mental illness was significant. The women who reported they experienced rape as an adult were $153 \%$ more likely to report a mental illness diagnosis. In other words, a higher likelihood of a mental health diagnosis was associated with being raped under the age of 18. Again, Black was significantly and negatively related. Blacks were $47 \%$ less likely (p. $\leq .01)$ to enter prison with a mental health diagnosis.

The results for Hypothesis 4 are presented in Model 4. The relationship between the cumulative victimization score and receiving a mental illness diagnosis before incarceration was statistically significant. For each additional type of victimization, the likelihood of reporting a mental illness diagnosis before incarceration increased by $76 \%$. As found in the preceding models, blacks were $44 \%$ $(\mathrm{p} \leq .01)$ less likely than whites to report a pre-prison mental health diagnosis before going to prison. 
Table 3. Odds Ratios for Logistic Regression of Mental Health Diagnosis on Childhood Sexual Abuse, Rape Under 18, Rape over 18, and Cumulative Sexual Abuse, Controlling for Age, and Race.

\begin{tabular}{|c|c|c|c|c|c|c|c|c|}
\hline & \multicolumn{2}{|c|}{ Model 1} & \multicolumn{2}{|c|}{ Model 2} & \multicolumn{2}{|c|}{ Model 3} & \multicolumn{2}{|c|}{ Model 4} \\
\hline & $\beta$ & $\begin{array}{l}\text { Odds } \\
\text { Ratio }\end{array}$ & $\beta$ & $\begin{array}{l}\text { Odds } \\
\text { Ratio }\end{array}$ & $\beta$ & $\begin{array}{l}\text { Odds } \\
\text { Ratio }\end{array}$ & $\beta$ & $\begin{array}{l}\text { Odds } \\
\text { Ratio }\end{array}$ \\
\hline \multicolumn{9}{|l|}{ Sexual Abuse } \\
\hline $\begin{array}{l}\text { Childhood } \\
\text { Abuse }\end{array}$ & .73 & $2.07^{* * *}$ & & - & & - & & - \\
\hline Rape $<$ Age 18 & & - & .80 & $2.23^{* * *}$ & & - & & - \\
\hline Rape $>$ Age 18 & & - & & - & .93 & $2.53^{* * *}$ & & - \\
\hline Cumulative & & - & & - & & - & .56 & $1.70^{* * *}$ \\
\hline \multicolumn{9}{|l|}{ Control Variables } \\
\hline Age & .01 & 1.01 & .01 & 1.01 & .00 & 1.00 & .01 & 1.01 \\
\hline Black & -.64 & $0.53^{* *}$ & -.67 & $.51^{* * *}$ & -.64 & $0.53^{* *}$ & -.54 & $0.56^{* *}$ \\
\hline $\begin{array}{l}\text { Native Ameri- } \\
\text { can }\end{array}$ & -.22 & .80 & -.18 & 0.83 & -.33 & 0.72 & -.29 & 0.75 \\
\hline Other Race & -.38 & 0.68 & -.36 & 0.70 & -.35 & 0.71 & -.39 & 0.68 \\
\hline $\begin{array}{l}-2 \text { Log Likeli- } \\
\text { hood }\end{array}$ & & 991.70 & & 995.96 & & 3.74 & & 62.700 \\
\hline Nagelkerke R² & & .07 & & .06 & & 9 & & .12 \\
\hline
\end{tabular}

\section{Sexual Victimization and Current Depression}

Table 4 reports the results for the Ordinary Least Squares (OLS) regressions of Current Depression on each of the sexual victimization variables. The results for Hypothesis 5 are presented in Model 1. Only one variable was significant. After controlling for age and race, those who reported experiencing Childhood Sexual Abuse scored 2.99 points higher on the CESD-R, (b=2.99, $p$ $\leq$.001).

The results for Hypothesis 6, Current Depression regressed on Rape under Age 18 (controlling for age and race) are presented in Model 2. Only one variable was significant. Women who reported experiencing a rape before the age of 18 had scores about 4.27 points higher on the CESD-R scale, $(\mathrm{p} \leq .001)$ level compared to those who had not experienced rape before age 18 .

The results for Hypothesis 7 are reported in Model 3. Women who reported being raped as an adult had scores on the CESD-R that were 3.93 points higher than those who did not report experiencing a rape as an adult $(\mathrm{p} \leq .001)$ while controlling for age and race. 
The results for Hypothesis 8 are presented in Model 4. The only significant variable in this model is Cumulative Sexual Victimization. For each added type of victimization, on average the scores on the CESD-R increased 2.43 points $(\mathrm{p} \leq .001)$, controlling for age and race.

Table 4. OLS Regression of Current Level of Depression on Childhood Sexual Abuse, Controlling for Age, and Race

\begin{tabular}{|c|c|c|c|c|}
\hline & Model 1 & Model 2 & Model 3 & Model 4 \\
\hline \multicolumn{5}{|l|}{ Sexual Victimization } \\
\hline Childhood Abuse & $\begin{array}{c}2.99 * * * \\
(.14)\end{array}$ & - & - & - \\
\hline Rape $<$ Age 18 & - & $\begin{array}{c}4.27^{* * *} \\
(.16)\end{array}$ & - & - \\
\hline Rape $>$ Age 18 & - & - & $\begin{array}{l}3.93^{* * * *} \\
(.18)\end{array}$ & - \\
\hline Cumulative Abuse & - & - & - & $\begin{array}{l}2.43^{* * *} \\
(.38)\end{array}$ \\
\hline \multicolumn{5}{|l|}{ Control Variables } \\
\hline Age & $\begin{array}{l}-0.01 \\
(-.13)\end{array}$ & $\begin{array}{c}-0.02 \\
(.16)\end{array}$ & $\begin{array}{l}-0.05 \\
(-.05)\end{array}$ & $\begin{array}{l}-0.03 \\
(-.03)\end{array}$ \\
\hline Black & $\begin{array}{l}0.29 \\
(.01)\end{array}$ & $\begin{array}{l}-0.26 \\
(-.02)\end{array}$ & $\begin{array}{l}0.40 \\
(.02)\end{array}$ & $\begin{array}{l}0.72 \\
(-.03)\end{array}$ \\
\hline Native American & $\begin{array}{l}1.15 \\
(.04)\end{array}$ & $\begin{array}{l}1.30 \\
(.48)\end{array}$ & $\begin{array}{l}0.79 \\
(.03)\end{array}$ & $\begin{array}{l}.90 \\
(.03)\end{array}$ \\
\hline Other Race & $\begin{array}{l}1.64 \\
(.04)\end{array}$ & $\begin{array}{l}1.72 \\
(.42)\end{array}$ & $\begin{array}{l}1.77 \\
(.04)\end{array}$ & $\begin{array}{l}1.64 \\
(.04)\end{array}$ \\
\hline $\mathrm{R}^{2}$ & 0.02 & 0.03 & 0.03 & 0.05 \\
\hline
\end{tabular}

Note: Unstandardized coefficients are presented. Standard coefficients are in parentheses.

${ }^{*} p \leq .05{ }^{* *} p \leq .01{ }^{* * *} p \leq .001$

\section{DISCUSSION AND CONCLUSIONS}

The current study adds to current knowledge about the relationship between sexual abuse and mental health issues among women prisoners through the examination of the individual and cumulative effects of childhood sexual abuse, childhood rape, and adult rape. First, our findings confirm prior research about the prevalence of childhood sexual abuse among women prisoners with more 
than half of the respondents reported experiencing childhood sexual abuse, similar to past research (Gilfus, 2002; Heney \& Kristiansen, 1998; MarcusMendoza \& Wright, 2003; McClellan et al., 1997; Zlotnick, 1997). Additionally, we provide evidence of the prevalence of two other forms of sexual victimization among women prisoners. Finally, our finding that over forty percent of our sample had a prior mental health diagnosis is also in line with prior estimates of the prevalence of mental illness among women prisoners (Pollock, 2002).

However, we go further than simply confirming what is already known about sexual victimization and mental health issues among women prisoners. This study provides a link between the two in a sample of women prisoners, focusing on three different types of victimization. As we anticipated, sexual victimization and mental health issues were significantly and strongly related. Childhood sexual abuse, rape before the age of 18 and rape after the age of 18 were all related to entering prison with a mental health diagnosis as well as to current levels of depression. Furthermore, there was an additive effect of sexual victimization, with women who experienced more than one form of sexual victimization being more likely to report prior mental health diagnoses and to score higher on CESD$\mathrm{R}$ than those who experienced fewer types of sexual victimization. The addition of each type of sexual victimization increased the likelihood of both prior mental health diagnosis and higher rates of depressive symptoms.

We did, however, find some differences in the relationships of the different forms of sexual victimization with past and current mental health problems in our sample. Experiencing rape as an adult was related to the greatest likelihood of having a mental health diagnosis before prison, but experiencing a rape under the age of 18 was related to the highest increase in CESD-R scores. However, rape under the age of 18 was still strongly related to the likelihood of a mental health diagnosis before incarceration, while rape over the age of 18 was also strongly related to higher CESD-R scores. More notably, both relationships were stronger than the relationship between childhood sexual abuse and the two mental health variables. This is an important and interesting finding.

Much of the earlier work has focused on the link between childhood sexual abuse and mental health problems (Belknap \& Holsinger, 2006; Browne \& Finkelhor, 1986; Heney \& Kristiansen, 1998). Our research confirms that link does exist. Regarding pathways explanations of female crime, it is an important link. Young girls who have survived childhood sexual abuse often begin using drugs to self-medicate emotional and mental problems that result from childhood sexual abuse (Owen, 1998; Sharp, 2014). However, more recent forms of sexual victimization appear to be even more salient in the development of mental health issues as well as in current levels of depression. This has implications for programming in prison. First, in selecting those to participate in trauma-informed therapy, all three types of sexual trauma must be considered. Second, the programming itself must take into account the types of trauma experienced by each woman. For example, childhood sexual abuse is more likely to be perpetrated by a caregiver of the child, someone she depends on. This can lead to a sense of betrayal and difficulty developing trust with those in authority positions (Finkelhor \& Browne, 1985). Experiencing rape as an adolescent or adult may be linked to difficulty in relationships with males, suggesting that care should be taken in the staffing of programs for these women (Marcus-Mendoza \& Wright, 2003). 
Furthermore, the more types of victimization experienced, the greater the risk. For those who experienced more than one type of victimization, the cumulative impact suggests that each additional type of sexual victimization experienced greatly increases the likelihood of both entering prison with a mental health diagnosis and reporting current depressive symptomology. Specifically, for each added event, the odds of entering prison with a mental health disorder increased by $76 \%$. Therefore someone experiencing all 3 types of victimization was $228 \%$ more likely to enter prison with a mental health disorder. Furthermore, those who experienced all victimization types scored 7.29 points higher on the CESD scale than those who did not experience any type of victimization. Our findings suggest that each type of sexual victimization has a separate impact as well as a cumulative impact on the past and current mental health status of the women in this study, highlighting the individual contributions of specific forms of sexual victimization on mental health problems.

This is similar to the approach of the ACE study, which argues that the more types of childhood adversity one has experienced, the greater the likelihood of experiencing problems in adulthood (Dube et al., 2003; Edwards et al., 2003; Messina et al., 2007). However, unlike the ACE study, which focuses on the cumulative impact of a wide range of adverse experiences during childhood only (Dube et al., 2003; Felitti et al., 1998), we have examined a specific type of adversity, sexual victimization, in both childhood and adulthood. However, our study is limited to only one type of adversity, and many different types of trauma may occur, and probably have occurred, in the lives of women prisoners. Our goal was not to argue that sexual victimization is the sole or even primary cause of mental health problems in this population but rather to explore whether different forms of sexual trauma have different relationships with the mental health of women prisoners.

Nearly one-third of the women in the current sample reported one type of sexual victimization, and more than an additional third reported experiencing more than one. In this sample, it appears that victimization does not always occur as a separate and unique event. Instead, those who experience sexual abuse or rape as a child may be at higher risk of experiencing additional types of sexual trauma. This has important implications for treatment. Finkelhor and Browne (1985) contend that for childhood sexual abuse survivors, this may result in traumatic sexualization, betrayal, stigmatization, and or powerlessness. Thus, programs like Covington's (2003) Beyond Trauma, which has been adapted for use in correctional settings, would be important tools for those working with women prisoners. We would suggest appropriate trauma-informed interventions as well as evaluation of prison practices if we are to truly rehabilitate incarcerated women.

The findings also point to the need for trauma-informed interventions before incarceration. If sexual trauma is a strain that leads some women on a pathway to prison (Owen, 1998; Sharp, 2014), then intervention and treatment may help to prevent future offending (Bloom, Owen \& Covington, 2004; Covington, 2003). Perhaps, high schools or middle schools could offer some type of support to girls who have been victimized to prevent strains that may lead to future victimization and other negative outcomes that stem from experiencing sexual trauma (Schilling \& Aseltine, 2007).

By examining multiple types of sexual victimization, we found that regardless of the timing, sexual trauma is related to mental health problems for women. The inclusion of a cumulative index demonstrates that not only do women go to 
prison with a history of abuse and trauma but also that many have experienced multiple traumas, compounding their mental health needs. Bloom et al. (2004) point out that policy within the criminal justice system was created to deal with male prisoners. In the best of situations, this can lead to an environment characterized by practices that may re-traumatize the women in prison (Bloom et al., 2004; Covington \& Bloom, 2003; Heney \& Kristiansen, 1998; Marcus-Mendoza \& Wright, 2003).

The need for a three-fold approach is evident; policies that guide the management of women prisoners should be addressed to ensure that no additional harm is being done and appropriate mental health treatment should be administered. Additionally, mental health treatment for past trauma should be offered to prisoners to ensure that they leave prison able to function successfully in their communities. Finally, more policies are needed to both protect girls and women from sexual victimization and to repair the harm when it does occur.

It is also noteworthy that being black, as compared to white, was related to a decreased likelihood of prior mental health diagnosis, but not to current depression. The reasons for this are beyond the scope of this study. However this seems to suggest needs without a prior formal diagnosis. We suggest that while there is no difference in how the two races respond to sexual trauma, there is a difference in access to health care as well as in how the two races are viewed by gatekeepers in the mental health system. Young (1986) pointed out that for black females, unlike their white counterparts, there is no good girl category. Likewise, Steffensmeier and colleagues $(1996 ; 2001)$ have pointed out that minority offenders are often seen as more blameworthy. These prejudicial attitudes may also come into play in the mental health system, wherein white women may be seen as needing help, while black women may be viewed as belligerent or lazy (Morris, 2007).

There are several limitations to this study that future research should address. Ideally, research should examine not only incarcerated women but women in the general population who have histories of mental illness and sexual victimization. This could help us identify both protective factors that may mitigate the impact of sexual trauma. Additionally, more research is needed on the life histories of incarcerated women above and beyond their trauma histories. As noted above, we do not claim that sexual victimization, or indeed trauma alone is the cause of incarceration. Additionally, there are many other forms of trauma that should be explored. It is important to note that our measure of going to prison with a mental health diagnosis is dependent on the respondents' recall of being given a diagnosis. Future studies might consider using an alternative method to cross check the information. Our goal has been limited to expanding our understanding of the relationship between sexual victimization and mental health problems among women prisoners.

Finally, in the absence of eradicating sexual violence against women, we recommend that further research should be conducted focusing on specific types of mental illnesses and how these are linked to trauma. By more clearly identifying the linkages, more appropriate treatment responses can be developed. Ideally, there would be an end to violence against women, however without this end, responsiveness to early symptoms of distress might improve life chances women who have been through trauma. We contend that in many cases these women would be far better served through appropriate treatment rather than incarceration. However, for those survivors of sexual trauma who are or will be in the criminal justice system, it is imperative that programs be implemented to begin addressing the effects of that trauma. 


\section{ACKNOWLEDGMENTS}

Dignity thanks the following reviewers for their time and expertise: Kathryn Quina, Emerita Associate Dean and Professor (Psychology and Gender and Women's Studies), University of Rhode Island; and Mary Anne Layden, Assistant Professor of Clinical Psychology; Director, Sexual Trauma and Psychopathology Program, Department of Psychiatry, University of Pennsylvania, USA.

\section{AUTHOR BIOGRAPHIES}

Jennifer M. Hartsfield, Ph.D., (orcid.org/0000-0003-4722-0046) is Assistant Professor in the department of Criminal Justice at Bridgewater State University in Bridgewater, MA. Her research focuses on gender, trauma, and mental health in the criminal justice system. Email: jennifer.hartsfield@bridgew.edu

Susan F. Sharp, Ph.D., is the David Ross Boyd Professor in the Department of Sociology and the Women's and Gender Studies Program. Her research has spanned two decades of criminal justice policies and impacts in the state of Oklahoma, and she has authored two books, edited two books, and published numerous journal articles on gender, crime, deviance, and criminal justice.

Dr. Sonya Conner, Ph.D., is an Assistant Professor of Sociology at Worcester State University in Worcester, Massachusetts. Her research focuses on inequalities in education and the criminal justice system. Email: sconner@worcester.edu

\section{RECOMMENDED CITATION}

Hartsfield, Jennifer, Sharp, Susan F. \& Conner, Sonya. Cumulative victimization and mental health outcomes among incarcerated women. Dignity: A Journal of Sexual Exploitation and Violence. Vol. 2, Issue 1, Article 11. doi:10.23860/dignity.2017.02.01.11. Available at http://digitalcommons.uri.edu/dignity/vol2/iss1/11.

\section{REFERENCES}

Agnew, R. (1992). Foundation for a General Strain Theory of crime and delinquency. Criminology, 30, 47-87.

Agnew, R. (2005). Why do criminals offend?: A general theory of crime and delinquency. LA, California, Roxbury Publishing.

Asberg, K. \& Renk, K. (2012). Comparing incarcerated and college student women with histories of childhood sexual abuse: The roles of abuse severity, support, and substance use. Psychological Trauma: Theory, Research, Practice, and Policy. Advance online publication. Doi:10.1037/a0027162

Banyard, V.L., Williams, L. M. \& Siegel, J.A. (2001). The long-term mental health consequences of child sexual abuse: An exploratory study of the impact of multiple traumas in a sample of women. Journal of Traumatic Stress, 14, 697715 .

Barnes, J. E., Noll, J.G., Putnam, F.R. \& Penelope K. Trickett, P.K. (2009). Sexual and physical revictimization among victims of severe childhood sexual abuse. Child Abuse \& Neglect, 33, 412-420. 
Belknap, J. (1996). Access to programs and health care for incarcerated women. Federal Probation, 60, 34-39.

Belknap, J. \& Holsinger, K. (2006). The gendered nature of risk factors for delinquency. Feminist Criminology, 1, 48-71.

Bloom, B. E., Owen, B. \& Covington, S. (2004). Women offenders and the gendered effects of public policy. Review of Policy Research, 21, 31-48.

Browne, A. \& Finkelhor, D. (1986). Impact of child sexual abuse: a review of the research. Psychological Bulletin, 99, 66-77.

Carson, E. A \& Golinelli. D. (2013). Prisoners in 2012 - Advance Counts. Washington, DC: Bureau of Justice Statistics/National Institute of Justice (NCJ 242467).

Catalano, S., Smith, E., Snyder, H. \& Rand, M. (2009). Female victims of violence. Bureau of Justice Statistics Special Selected Findings, NCJ 228356. Washington D.C.: U.S. Department of Justice.

Center for Epidemiological Studies of Depression. (n.d.) CESD-R scale. Retrieved June 20, 2014 from http://cesd-r.com

Chesney-Lind, M. (1986). Women and crime: The female offender. Signs: Journal of Women in Culture and Society, 12, 78-96. . (2003). Reinventing women's corrections. In S. F. Sharp (Ed.), The Incarcerated woman, 3-14. Upper Saddle River: Prentice Hall.

Chesney-Lind, M. \& Pasko, L. (2004). The female offender: Girls, women and crime (2nd ed.). Thousand Oaks, CA: Sage.

Clark, C. B., Perkins, A., McCullum-Smith, C.B., Islam, M.A., Hanover, E.E., \& Cropsey, K.L. (2012). Characteristics of victims of sexual abuse by gender and race in a community corrections population. Journal of Interpersonal Violence, 12, 1844-1861.

Covington, S. S. (2003). Beyond trauma: A healing journey for women. Center City, MN: Hazelden.

Covington, S. S. \& Bloom, B.E. (2003). Gendered justice: Women in the criminal justice system. In B. E. Bloom (Ed.), Gendered justice: Addressing female offenders. Carolina Academic Press.

Dube, S.R., Anda, R.F., Whitfield, C.L., Brown, D., Felitti, V., Dong, M. \& Giles, W.H. (2005). Long-term consequences of childhood sexual abuse by gender of victim. American Journal of Preventative Medicine, 28, 430-438.

Dube, S.R., Felitti, V.J., Dong, M., Giles, W. H. \& Anda, R. F. (2003). The impact of adverse childhood experiences on health problems: Evidence from four birth cohorts dating back to 1900." Preventative Medicine, 3, 268-277.

Eaton, W.W., Smith, C., Ybarra, M., C., \& Tien, A. (2004). Center for Epidemiologic Studies Scale: Review and revision (CESD and CESD-R). In ME Maruish (Ed). The use of psychological testing for treatment planning and outcomes assessment ( $3^{\text {rd }}$ Ed), Volume 3: Instruments for Adults, pp. 363-377. Mahwah, NJ: Lawrence Erlbaum.

Edwards, V.J., Holden, G.W., Felitti, V.J. \& Anda, R.F. (2003). Relationship between multiple forms of childhood maltreatment and adult mental health in community respondents: Results from the Adverse Childhood Experiences Study. American Journal of Psychiatry 160, 1453-1460.

Felitti, V.J., Anda, R.F., Nordenberg, D., Williamson, D.F., Spitz, A.M., Edwards, V., Koss, M. P. \& Marks, J.S. (1998). Relationship of childhood abuse and household dysfunction to many of the leading causes of death in adults: The Adverse Childhood Experiences (ACE) Study. American Journal of Preventative Medicine, 14, 245-258. 
Finkelhor, D. \& Browne, A. (1985). The traumatic impact of child sexual abuse: a conceptualization. American Journal of Orthopsychiatry, 55, 530-541.

Finkelhor, D. \& Dziuba-Leatherman, J. (1994). Children as victims of violence: a national survey. Pediatrics, 94, 413-420.

Gidycz, C.A. \& Mary P. Koss, M.P. (1989). The impact of adolescent sexual victimization: Standardized measures of anxiety, depression, and behavioral deviancy. Violence \& Victims, 4, 139-149.

Gilfus, M.E. (2002). Women's experiences of abuse as a risk factor for incarceration. http://www.vawnet.org/.

Harrison, P.M. \& Beck, A.J. (2005). Bureau of Justice Statistics Bulletin: Prisoners in 2004. Washington, DC: Bureau of Justice Statistics/National Institute of Justice (NCJ 210677).

Heney, J. \& Kristiansen, C.M. (1998). An analysis of the impact of prison on women survivors of childhood sexual abuse. Women \& Therapy, 20,29-44.

Humphrey, J.A. \& White, J.W. (2000). Women's vulnerability to sexual assault from adolescence to young adulthood. Journal of Adolescent Health, 27, 419-424.

James, D.J. \& Glaze, L.E. (2006). Mental Health Problems of Prison and Jail Inmates. Bureau of Justice Statistics Special Report, NCJ 213600. Washington, D.C.: U.S. Department of Justice.

Krupnick, J. L., Green, B.L., Stockton, P., Goodman, L., Corcoran, C. \& Petty, R. (2004). Mental health effects of adolescent trauma exposure in a female college student sample: Exploring differential outcomes based on experiences of unique trauma types and dimensions. Psychiatry, 67, 264-279.

Marcus-Mendoza, S.T. \& Wright, E. (2003). Treating the woman prisoner. In S.F. Sharp (Ed.), The Incarcerated Female. Upper Saddle River: Prentice Hall.

Messina, N., Grella, C., Burdon, W., \& Prendergast, M. (2007). Childhood adverse events and current traumatic distress: A comparison of men and women drugdependent prisoners. Criminal Justice \& Behavior, 34, 1385-1401.

McClellan, D.S., Farabee, D., \& Ben M. Crouch, B.M. (1997). Early victimization, drug use, and criminality: A comparison of male and female prisoners. Criminal Justice \& Behavior, 24, 455-476.

Morris, E. W. (2007). "Ladies" or "loudies"? Perceptions and experiences of black girls in classrooms. Youth \& Society, 38(4), 490-515.

Owen, B. (1998). "In the mix": Struggle and survival in a women's prison. Albany, NY: State University of New York Press.

Pollock, J.M. (2002). Women, prison, and crime. Canada: Wadsworth.

Radloff, S. (1977). The CESD-R scale: A self-report depression scale for research in the general population. Journal of Applied Psychological Measurement, 1, 385401.

Reddington, F.P. \& Kreisel, B.W. (2005). Sexual assault: The victims, the perpetrators, and the criminal justice system. Durham, North Carolina: Carolina Academic Press.

Schilling, E.A., Aseltine, R.A. \& Gore, S. (2007). Young women's social and occupational development and mental health in the aftermath of childhood sexual abuse. American Journal of Community Psychology, 40, 109-124.

Sharp, S.F. (2014). Mean lives, mean laws: Oklahoma's women prisoners. Piscaway, NJ: Rutgers University Press.

Sharp, S.F., Peck, B.M., \& Hartsfield, J. (2012). Childhood adversity and substance use of women prisoners: A General Strain Theory approach. Journal of Criminal Justice, 40(3), 202211. 
Shelden, R.G. (2001). Controlling the dangerous classes. Needham Heights: Pearson Education.

Steffensmeier, D., Ulmer, J. \& Kramer, J. (1998). The interaction of race, gender and age in criminal sentencing: The cost of being young, black and male. Criminology, 36, 763-793.

Steffensmeier, D. \& Demuth, S. (2001). Ethnicity and judges' sentencing decisions: Hispanic-black-white comparisons. Criminology 39, 145-178.

Substance Abuse and Mental Health Services Administration (SAMHSA), Center for Behavioral Health Statistics and Quality. (2014, February 28). The NSDUH report: State Estimations of Adult Mental Illness form 2011 and 2012 surveys on drug use and health. Rockville. MD.

Walsh, K., Dilillo, D., \& Scalora, M.J. (2011). The cumulative impact of sexual revictimization on emotion regulation difficulties: An examination of female inmates. Violence Against Women, 17, 1103-1118.

Widom, C.S. \& Morris, S. (1997). Accuracy of adult recollections on childhood victimization: part 2. childhood sexual abuse. Psychological Assessment, 9, 34-46.

Young, V. (1986). Gender expectations and their impact on black female victims and offenders. Justice Quarterly, 3, 305-327.

Zlotnick, C. (1997). Posttraumatic stress disorder (PTSD), PTSD comorbidity, and childhood abuse among incarcerated women. The Journal of Nervous \& Mental Disease, 185, 761-763. 